\title{
Ingrown Toenail
}

National Cancer Institute

\section{Source}

National Cancer Institute. Ingrown Toenail. NCI Thesaurus. Code C34836.

A condition in which the nail grows into the nailbed secondary to downward pressure, generally caused by ill-fitting shoes. Symptoms include pain, erythema, and edema, and may result in infection if it remains untreated. 